\title{
ARTICLE \\ Clinical characteristics and related risk factors of disease severity in 101 COVID-19 patients hospitalized in Wuhan, China
}

\author{
Xue-qing Liu ${ }^{1,2}$, Shan $\mathrm{Xue}^{1,2}$, Jia-bo $\mathrm{Xu}^{1,2}$, Heng Ge ${ }^{2,3}$, Qing Mao ${ }^{2,4}$, Xin-hui $\mathrm{Xu}^{2,5}$ and Han-dong Jiang ${ }^{1,2}$
}

\begin{abstract}
Coronavirus disease 2019 (COVID-19) broke out in December 2019. Due its high morbility and mortality, it is necessary to summarize the clinical characteristics of COVID-19 patients to provide more theoretical basis for future treatment. In the current study, we conducted a retrospective analysis of the clinical characteristics of COVID-19 patients and explored the risk factors for the severity of illness. A total of 101 COVID-19 patients hospitalized in Leishenshan Hospital (Wuhan, China) was classified into three sub-types: moderate $(n=47)$, severe $(n=36)$, and critical $(n=18)$; their clinical data were collected from the Electronic Medical Record. We showed that among the 101 COVID-19 patients, the median age was 62 years (IQR 51-74); 50 (49.5\%) patients were accompanied by hypertension, while $25(24.8 \%)$ and $22(21.8 \%)$ patients suffered from diabetes and heart diseases, respectively, with complications. All patients were from Wuhan who had a definite history of exposure to the epidemic area. Multivariate logistic regression analysis revealed that older age, diabetes, chronic liver disease, percentage of neutrophils (N\%) $>75 \%$, CRP $>4 \mathrm{mg} / \mathrm{L}$, D-dimer $>0.55 \mathrm{mg} / \mathrm{L}, \mathrm{IL}-2 \mathrm{R}>710 \mathrm{U} / \mathrm{mL}, \mathrm{IL}-8>62 \mathrm{pg} / \mathrm{mL}$, and IL- $10>9.1 \mathrm{pg} / \mathrm{mL}$ were independent variables associated with severe COVID-19. In conclusion, we have identified the independent risk factors for the severity of COVID-19 pneumonia, including older age, diabetes, chronic liver disease, higher levels of N\%, CRP, D-dimer, IL-2R, IL-8, and IL-10, providing evidence for more accurate risk prediction.
\end{abstract}

Keywords: coronavirus disease 2019 (COVID-19); severe acute respiratory syndrome coronavirus 2 (SARS-CoV-2); clinical features; risk factors; disease severity; retrospective analysis

Acta Pharmacologica Sinica (2022) 43:64-75; https://doi.org/10.1038/s41401-021-00627-2

\section{INTRODUCTION}

As a highly contagious disease, coronavirus disease 2019 (COVID19)-induced pneumonia was first reported in Wuhan, Hubei Province, China, in December 2019 and then broke out in other provinces of China and overseas [1]. The World Health Organization declared ongoing COVID-19 a public health emergency of international concern on January 30, 2020 [2]. Under strict prevention and control strategies, new cases of COVID-19 in China have been rapidly reduced, and the epidemic has been effectively managed. However, the epidemic has constituted a considerable challenge worldwide, and the global situation remains grim. As of June 29, 2020, there were over 10 million COVID-19 patients and more than 500,000 deaths worldwide. The numbers are still growing, greatly exceeding the numbers of cases and deaths caused by SARS or the Middle East respiratory syndrome (MERS) outbreaks in 2003 and 2013, respectively. However, the source of COVID-19 has not been identified, and there are currently no specific antiviral treatments. Therefore, it is necessary to summarize and analyze the clinical characteristics of
COVID-19 patients to provide a theoretical basis for future research and assistance in COVID-19 prevention and control. In this study, we retrospectively collected and analyzed the detailed clinical data of COVID-19 patients with varying disease severity from a hospital in Wuhan. The clinical characteristics of patients with COVID-19 pneumonia were described, and risk factors for the severity of COVID-19 were explored.

\section{METHODS}

Study design, setting, and participants

In this retrospective cohort study, 101 case subjects ( $\geq 18$ years old) with COVID-19 infection who were discharged from or died at Leishenshan Hospital (Wuhan, China) between February 23, 2020, and April 4, 2020, were included. According to the seventh edition of the COVID-19 diagnosis and treatment guide of the National Health Commission of China, the above patients were divided into three groups: moderate (mild and common, $n=47)$, severe $(n=$ $36)$, and critical $(n=18)$. The study was approved by the Research

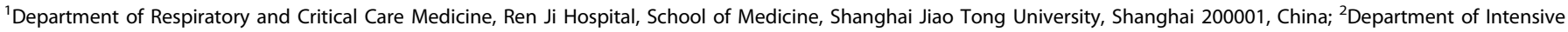

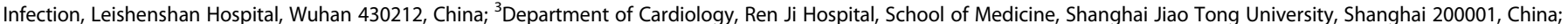

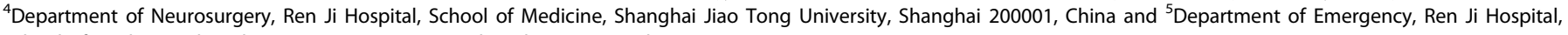
School of Medicine, Shanghai Jiao Tong University, Shanghai 200001, China

Correspondence: Heng Ge (dr.geheng@foxmail.com) or Qing Mao (neurojack@163.com) or Xin-hui Xu (xinhui_72@hotmail.com) or Han-dong Jiang (jianghd@163.com) These authors contributed equally: Xue-qing Liu, Shan Xue, Jia-bo Xu.
}

Received: 3 August 2020 Accepted: 10 February 2021

Published online: 19 March 2021 
Ethics Commission of the hospital, and the requirement for informed consent was given by the Ethics Commission.

\section{Data collection}

Epidemiological, clinical, laboratory, radiography, treatment, and outcome data were collected from electronic medical records. All data were extracted and examined by three clinicians independently.

\section{Statistical analysis}

For continuous variables, the mean (SD) and median (IQR) were used for normally and abnormally distributed data. Categorical variables were expressed as counts (\%). For laboratory tests, it was determined whether the measurement results were outside the normal range.

Principal component analysis (PCA) was carried out to extract the features, and dimension reduction was completed without losing important information on the variables. Based on the data integrated by PCA, cluster analysis was performed to determine the COVID-19 subgroups.

In this article, the chi-square test or Fisher's test was used to test an association between categorical variables, while ANOVA was used for continuous variables. We have presented our method in the table and figure legends to ensure that the readers can understand what statistical approaches we adopted for the given calculation. To identify the risk factors for the severity of COVID-19 illness in 101 patients, we performed univariate ordinal logistic regression by including 52 key characteristics as independent variables in the calculation, followed by fitting a multivariate ordinal logistic regression model with the significant variables selected from univariate ordinal logistic regression. Before fitting the ordinal logistic regression model, continuous variables of the indicators were converted into categorical variables according to their reference values. The univariate and multivariate cumulative logit models were fitted, with the levels of indicators in the moderate group as the reference. First, univariate ordinal logistic regression was used to investigate the potential predictors of severity. To exclude the insignificant variables in the univariate cumulative logit model, we further carried out a backward, stepwise, multivariate, ordered, and logistic regression analysis. The odds ratio of the $95 \%$ confidence interval $(\mathrm{Cl})$ was estimated by the ordinal logistic regression model. A two-sided $P$ value $<$ 0.05 was considered statistically significant. The R.3.6.3 and R packages (gtsummary, MASS, FactoMineR, tableone) were used for data analysis and statistics [3].

\section{RESULTS}

Demographics and clinical characteristics

A total of 101 adult patients with COVID-19 infection who were hospitalized at a Wuhan hospital between February 23, 2020, and April 4, 2020, were included in this study. On the basis of the seventh edition of the COVID-19 diagnosis and treatment guide of the National Health Commission in China, the above patients were divided into three groups: moderate (mild and common, $n=47$ ), severe $(n=36)$, and critical $(n=18)$. Among these patients, 14 patients died during hospitalization, and 87 were discharged or transferred to a general hospital for other treatments. As shown in Table 1, the median age of the 101 patients was 62 years (IQR 51-74). The severe or critical patients were older (69.5 years, (IQR 62-80.5), and 72.5 years, (IQR 62.25-79.75) than the moderate patients (52 years, (IQR 40.5-62)). There were more male (56, $55.4 \%)$ than female $(45,44.6 \%)$ patients. All patients were from Wuhan and had a definite history of exposure to the epidemic area, of whom 55 patients (54.4\%) had been in close contact with patients diagnosed with COVID-19, 7 patients (6.9\%) had a cluster onset, and 39 patients (38.6\%) had no clear history of direct contact. There was no difference in exposure history or smoking history among the three groups. Nearly half of the patients (50, 49.5\%) had hypertension, which was also the most common primary comorbidity, followed by diabetes $(25,24.8 \%)$ and heart disease $(22,21.8 \%)$. The differences in the above three complications were statistically significant among the three groups. Additionally, clinical complications, such as chronic renal disease and cerebrovascular diseases, were significantly different among the groups. The difference in pulse and differential pressure among the three groups was statistically significant, and the differential pressure in critically ill patients was higher than that in moderate patients $(P<0.05)$. In terms of clinical presentation, fever $(65,64.4 \%)$ and cough $(59,58.4 \%)$ were the most common clinical features in these patients, while chest distress, dyspnea, fatigue, diarrhea and myalgia were also found. Symptoms such as runny nose and sore throat appeared less frequently and were therefore classified as other symptoms. Based on the SOFA score and CURB-65 score at admission, critically ill patients were in a more critical condition than patients with milder illness.

\section{Laboratory markers}

Key laboratory indicators for 101 patients on admission are summarized in detail (Table 2). In terms of routine blood tests, there were significant differences in the counts of white blood cells (WBCs), lymphocytes (L), and neutrophils $(\mathrm{N})$; the neutrophil-lymphocyte ratio (NLR); the percentage of neutrophils (N\%); the number of platelets (PLTs); and the hemoglobin (HB) level among the three groups. Among them, the $L$ count $(0.74$ [0.36]), PLT count $(125.00[85.00,194.00])$ and HB level (97.50 $[87.50,106.75])$ were lowest in critical patients, while the values for WBC (9.32 [6.21, 11.87]), N (8.18 [4.71]), NLR (12.33 [6.96]), and N\% (82.70 [8.94]) were relatively high. Concerning the infectionrelated parameters, the levels of inflammatory markers such as Creactive protein (CRP, 68.73 [44.82]) and the erythrocyte sedimentation rate (ESR, 48.22 [37.95]) were dramatically elevated in severely and critically ill patients and were positively correlated with the severity of pneumonia. In addition, the critical patients had higher levels of inflammatory cytokines, including interleukin (IL)-6 (556.44 [1390.84]), IL-2R (1410.06 [1490.60]), IL-8 (43.39 [73.60]), IL-10 (26.99 [33.9]) and tumor necrosis factor-alpha (TNFa, 17.70 [21.51]), than moderately severe patients. Additionally, there were also significant differences in PT among the three groups $(P<0.001)$, while the $D$-dimer level showed no difference among the groups. Moreover, the levels of indicators reflecting cardiac function, such as creatine kinase-MB (CK-MB, 4.19 [4.63]), myoglobin (Mb, 402.45 [928.54]), troponin I (TNI, 0.04 [0.04]), lactate dehydrogenase (LDH, 335.19 [170.24]), hydroxybutyrate dehydrogenase- $\mathrm{a}(\mathrm{HBDH}, 254.94$ [119.18]), and brain natriuretic peptide (BNP, 230.47 [398.42]), were significantly increased in patients with critical illness $(P<0.05)$. Moreover, the indicators of hepatorenal function, including glutamic oxaloacetic transaminase (GOT, 63.83 [97.64]), amylase (31.64 [36.75]), blood urea nitrogen (BUN, 17.18 [15.23]) and creatinine (CR, 17.18 [15.23]) levels, were higher in critical patients $(P<0.05)$, while the levels of albumin (ALB, 30.37 [4.94]) were lower. In addition, patients with severe and critically ill conditions had higher fasting blood glucose levels (6.42 [4.65]; 8.38 [6.54], respectively), which also corresponded to a higher rate of history of diabetes in the severe and critical patients. Otherwise, the levels of serum potassium (K), sodium ( $\mathrm{Na})$, and chlorine $(\mathrm{Cl})$ did not differ significantly among the three groups.

To explore the similarities and differences among patients in the moderate, severe and critical groups, PCA was performed based on a set of clinical factors. PCA is an unsupervised learning method and enables us to identify subgroups of patients sharing similar characteristics. As shown in the present study, the biplot from our PCA not only captured the patients with the same clinical symptoms (i.e., severity), but also showed the variables that were positively or negatively associated with the different severity categories. The contribution of each variable to the given 
Table 1. Demographics and clinical characteristics of 101 patients.

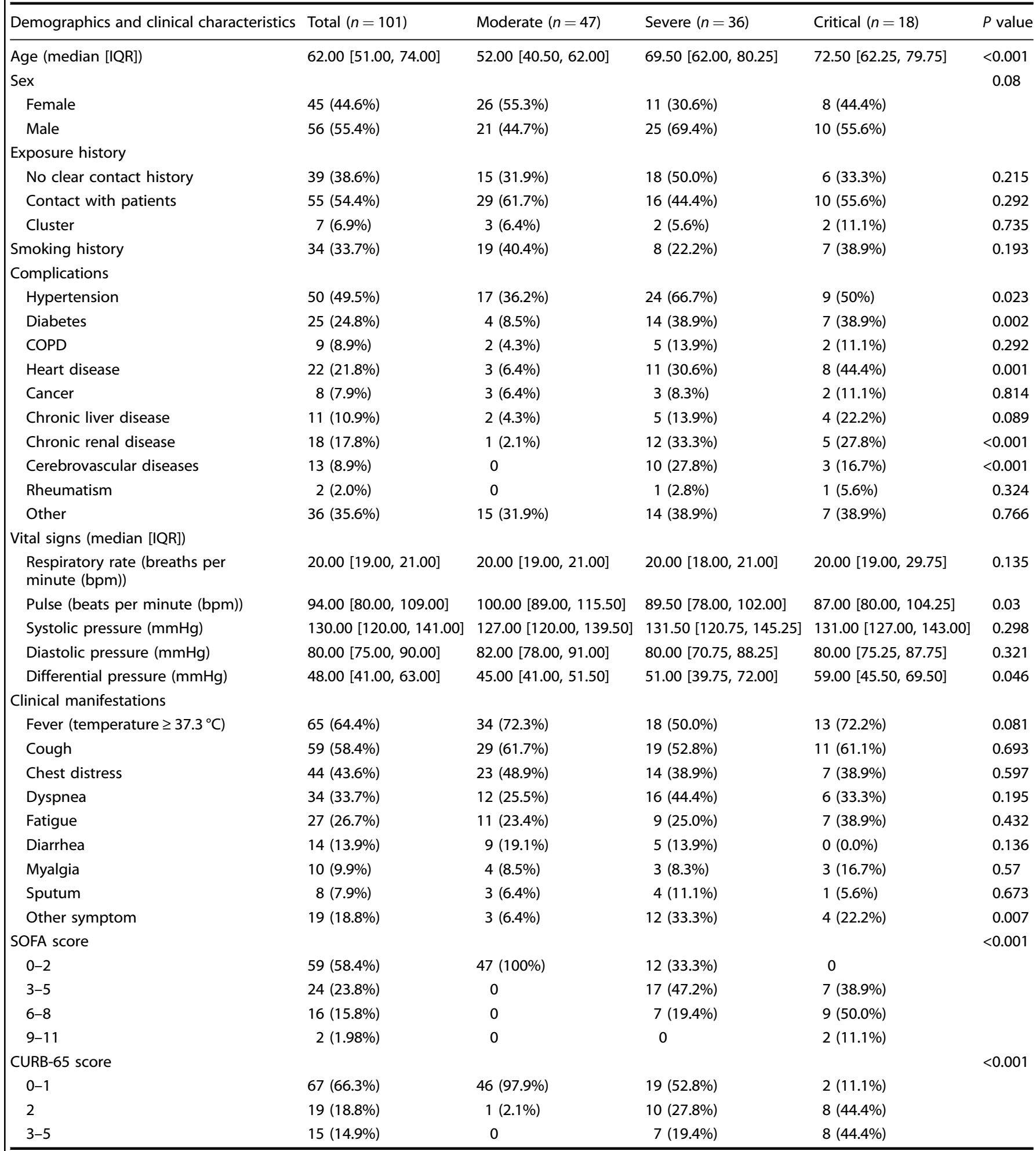

Data were shown as median, mean, $n(\%)$, or $n / N(\%)$. $P$ values were calculated by $X^{2}$ test, or Fisher's exact test, as appropriate.

SOFA Sequential organ failure assessment. CURB- 65 confusion, urea, respiratory rate, blood pressure plus age $\geq 65$ years.

subgroup is shown in Fig. 1. We found that the moderate patients had higher $L$ counts and levels of $H B$ and $A L B$, while the severe or critical patients featured higher BUN, MB, PCT, CRP, and IL-6 levels, etc.
Imaging manifestations

Due to the importance of radiography in the identification and diagnosis of COVID-19 pneumonia, all patients underwent a chest imaging examination on admission. After combining the imaging 


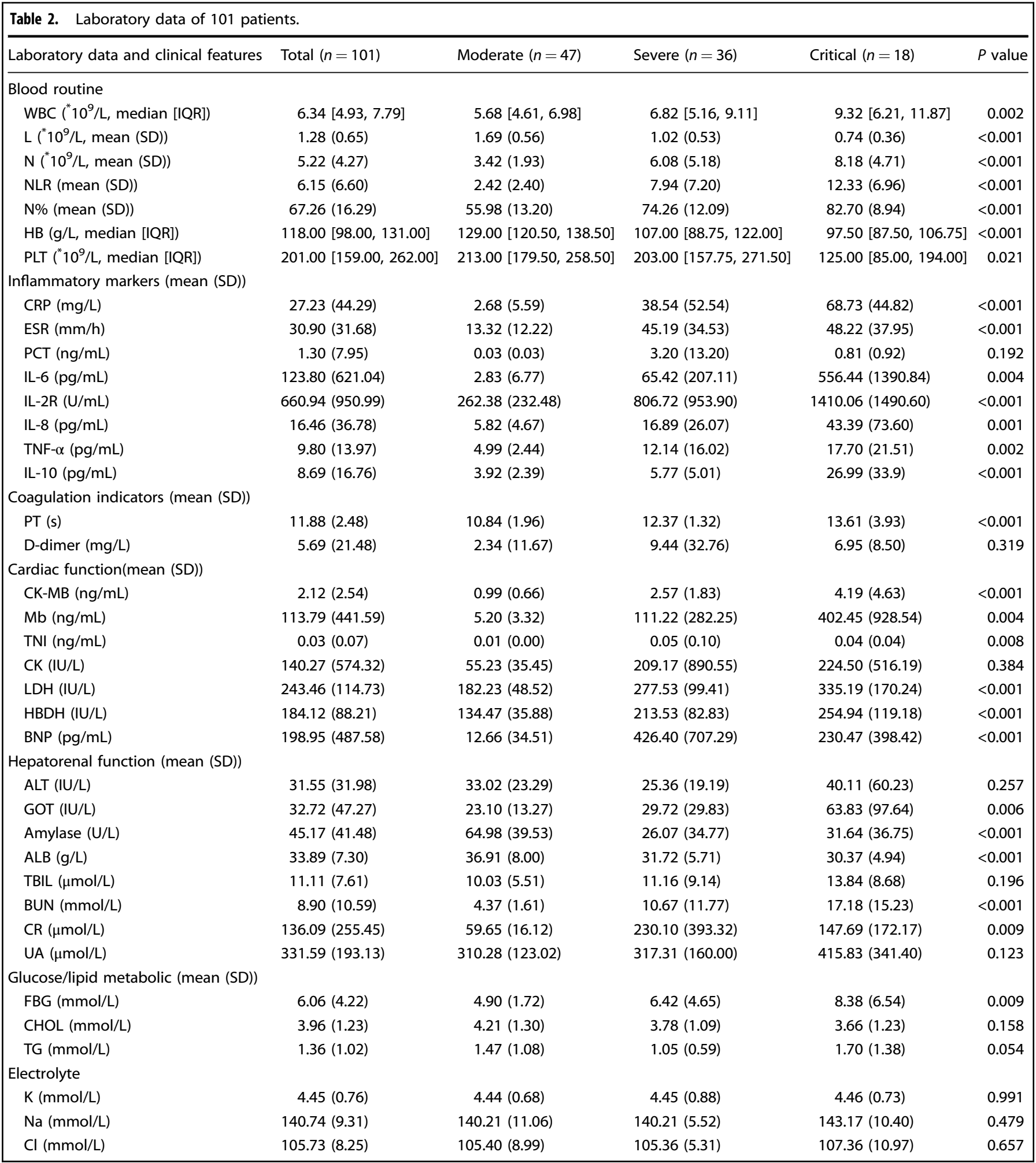

features, the characteristic patterns and distributions of CT manifestations were as follows: ground-glass opacification (GGO) $(92,91.1 \%)$, bilateral involvement $(92,91.1 \%)$, consolidation $(74$, $73.3 \%)$, subpleural distribution $(53,52.5 \%)$, and fibrosis $(41,40.6 \%)$ (Table 3). Bilateral ground-glass shadows and consolidation in the subpleural areas of the lungs were the most common imaging manifestations in our cases. There was no statistically significant difference in the above imaging characteristics between the two groups. However, fibrosis was more commonly seen on imaging of severe or critical patients than on that of moderate patients, which may be related to the rapid progression and longer onset time in more severe patients. Other CT findings included interlobular septal thickening, bronchiectasis, and pleural thickening (Fig. 2). 


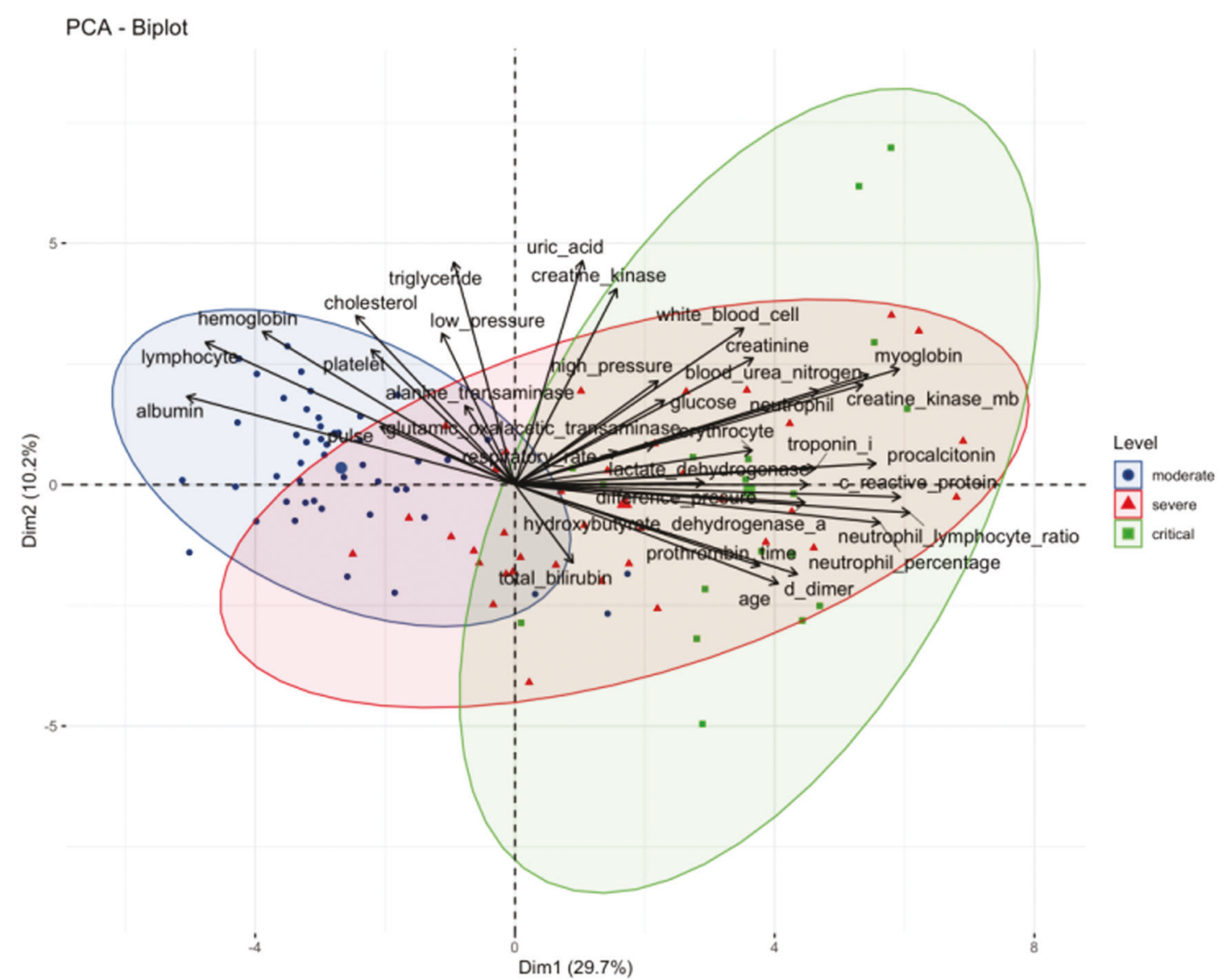

Fig. 1 PCA of the laboratory markers in COVID-19 patients with different disease severity. This section shows the correlation degree of continuous variables and the influence degree of each continuous variable on PCs.

Table 3. Image characteristics of 101 patients.

\begin{tabular}{|c|c|c|c|c|c|}
\hline Imaging features & Total $(n=101)$ & Moderate $(n=47)$ & Severe $(n=36)$ & Critical $(n=18)$ & $P$ value \\
\hline Bilateral involvement & 92 (91.1\%) & $44(93.6 \%)$ & 32 (91.4\%) & $16(88.9 \%)$ & 0.811 \\
\hline Subpleural distribution & $53(52.5 \%)$ & $28(59.6 \%)$ & $17(48.6 \%)$ & $8(44.4 \%)$ & 0.445 \\
\hline Fibrosis & 41 (40.6\%) & 13 (27.7\%) & 20 (57.1\%) & 8 (47.1\%) & 0.024 \\
\hline
\end{tabular}
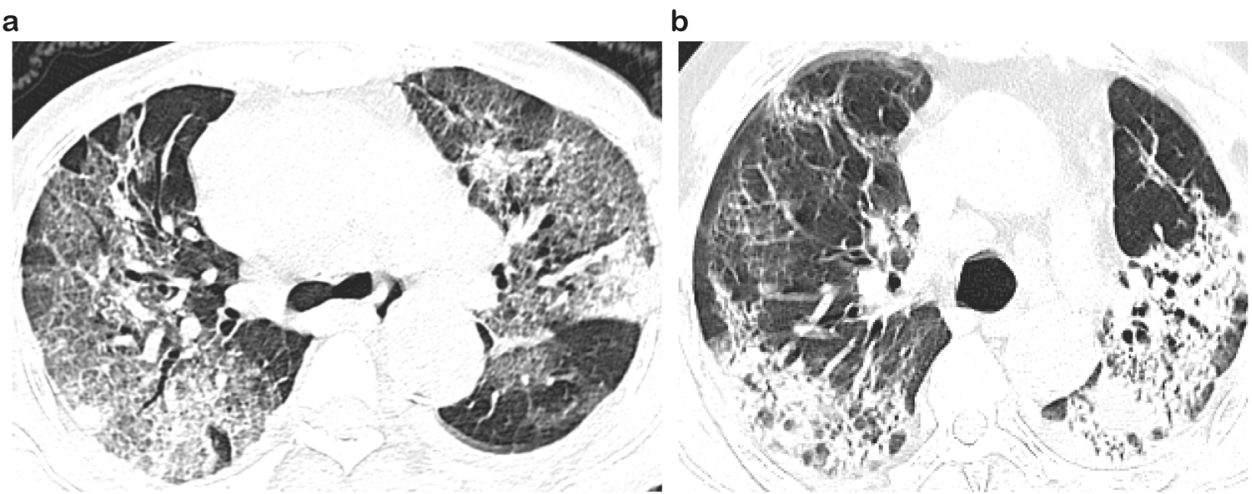

Fig. 2 Representative CT image of the COVID-19 patients. The CT image shows ground-glass opacification (GGO) in bilateral upper lungs with a little consolidation (a); CT radiography shows consolidation mainly in both lungs (b). 
Complications and treatments

Secondary infection (53 patients, 52.5\%) was the most common complication, followed by hypoproteinemia (52 patients, 51.5\%), respiratory failure (44 patients, 43.6\%), anemia (44 patients, 43.6\%), coagulation disorder (35 patients, 34.7\%), and acute respiratory distress syndrome (ARDS) (32 patients, 31.7\%). The results showed that the populations of severe or critical patients experiencing the above complications were greater than those of patients with moderate illness. Beyond that, sepsis, septic shock, heart failure, and acute renal injury also occurred more frequently in severe or critically ill patients than in mild patients $(P<0.05)$.

All patients were held in isolation with empiric and supportive medication. A total of 95 patients $(94.1 \%)$ received antiviral treatments, including ribavirin, arbidol, interferon-a sprays, oseltamivir and ganciclovir, of which the first two kinds of medicines were listed and most commonly used. As a representative proprietary Chinese medicine, Lianhua Qingwen capsule was used by 57 patients $(56.4 \%)$ in total, including 35 patients $(74.5 \%)$ with mild and moderate disease. Given that IL- 6 may be involved in the activation of multiple immune and inflammatory mediators contributing to respiratory failure in SARS-COV-2-infected patients, a human recombinant IL-6 receptor (IL-6R) - tocilizumab (not listed in Table 4) -was administered to two of the critical patients with significantly elevated IL-6 levels. Unfortunately, both patients ultimately died. Vitamin $C$ is a well-known antioxidant that has anti-inflammatory, antipathogen, and immune-enhancing properties [4, 5]. Thirty-five patients (34.7\%) were given vitamin $\mathrm{C}$ treatments. In addition, 72 patients $(71.3 \%)$ received antibiotic therapy, which included cephalosporins, quinolones, carbapenem, an enzyme inhibitor, linezolid, etc. Antifungal drugs were used at the appropriate time. In addition, $28 \%$ of patients $(27.7 \%)$ received glucocorticoids, and 17 patients (16.8\%) used gamma immunoglobulins. Additionally, anticoagulant therapy was administered in 34 patients (33.7\%). Continuous renal replacement therapy was administered to seven severe and critical patients (6.9\%) in the ICU. Proper nutrition support, such as albumin, early effective fluid infusion, and correction of electrolyte imbalances and acidosis, helped to save lives.

Oxygen therapy plays a critical role in the treatment process of patients. At the onset of illness, the majority of patients $(69,68.3 \%)$ received oxygen therapy, and only 32 patients (31.7\%) were treated without oxygen. Among the patients initially receiving nasal catheters, 16 patients (34.0\%) had moderate disease, 30 patients $(83.3 \%)$ had severe disease, and 7 patients $(38.9 \%)$ had critical disease. Mask oxygen inhalation was used by only one severely ill patient and one critically ill patient $(2.8 \%$ and $5.6 \%$, respectively), while high-flow oxygen inhalation was used by 4 severe and 2 critical patients $(11.1 \%$ and $11.1 \%$, respectively). Among critical patients, $3(16.7 \%)$ received noninvasive ventilation, and 5 (27.8\%) underwent tracheal intubation. In the course of the illness, an intermittent nasal catheter was used for oxygen inhalation in the vast majority of patients with mild symptoms. On discharge, 46 moderately ill patients (97.9\%) were able to discontinue oxygen, and only $1(2.1 \%)$ remained on oxygen. Among the critically ill patients, 6 (33.3\%) underwent noninvasive ventilation, 10 (55.6\%) underwent endotracheal intubation, and 2 (11.1\%) underwent ECMO. Encouragingly, one of the patients successfully weaned from ECMO, transitioning to ventilatorassisted ventilation and eventually to nasal catheterization for oxygen (Table 4).

The course of hospitalization of these patients is shown in Table 5. In general, the total hospitalization time of these patients was 40 days (IQR 28-49), of which the hospital stay of critically ill patients was the shortest, only 21.5 days (IQR 13.5-46). The median time from illness onset to first admission was 4 days (IQR 2-8) in patients with moderate disease, 19 days (IQR 10.5-30) in patients with severe disease, and 10.5 days (IQR 1.25-28.5) in patients with critical disease. For critically ill patients, the median time from illness onset to ICU admission was 21 days (IQR 6.25-33.75) and 29 days (IQR 15-36) for severely ill patients. Patients with critical illness had a longer length of stay in the hospital, with an average length of stay in the ICU of 12 days (IQR 5-20.75). The median time from admission to discharge was 20 days (IQR 14-27) for moderate patients, 10 days (IQR 7.75-16.25) for severe patients, and 13.5 days (IQR 5-18.5) for critically ill patients. The above indicators were significantly different between each two groups $(P<0.001)$.

\section{Risk factors for the severity of disease in 101 patients with} COVID-19

To identify the risk factors for the severity of COVID-19 illness in 101 patients, we performed univariate ordinal logistic regression by including 52 key characteristics as independent variables in the calculation. Before fitting the ordered logistic regression model, continuous variables were converted into categorical variables according to their reference values, and moderate illness was fitted as the reference level in the univariate cumulative logit model. As shown in Table 6, 36 variables were found to be associated with COVID-19 severity. Older age, diabetes, heart diseases, chronic renal disease, cerebrovascular diseases, chronic liver disease, WBC $\left(>10^{*} 10^{9} / \mathrm{L}\right), \mathrm{N} \%(>75 \%), \mathrm{N}$ $\left((1.8-6.3)^{*} 10^{9} / \mathrm{L} ;>6.3^{*} 10^{9} / \mathrm{L}\right), \mathrm{NLR}, \mathrm{CRP}(>4 \mathrm{mg} / \mathrm{L}), \mathrm{ESR}(>20 \mathrm{~mm} / \mathrm{h})$, PCT $(>0.05 \mathrm{ng} / \mathrm{mL})$, GOT ( $>35 \mathrm{IU} / \mathrm{L}), \mathrm{TBIL}(>21 \mu \mathrm{mol} / \mathrm{L}), \mathrm{BUN}(>7.6$ $\mathrm{mmol} / \mathrm{L}), \mathrm{CR}(>110 \mu \mathrm{mol} / \mathrm{L}), \mathrm{CKI}(>4.97 \mathrm{ng} / \mathrm{mL}), \mathrm{Mb}(>65 \mathrm{ng} / \mathrm{mL})$, TNI $(>0.04 \mathrm{ng} / \mathrm{mL}), \quad$ LDH $(>243 \mathrm{IU} / \mathrm{L}), \quad$ PT $(>13 \mathrm{~s}), \quad$ D-dimer (>0.55 mg/L), IL-6 (>7 pg/mL), IL-1 $\beta$ (>7 pg/mL), IL-2R ((223-710) $\mathrm{U} / \mathrm{mL} ;>710 \mathrm{U} / \mathrm{mL}), \quad \mathrm{IL}-8(>62 \mathrm{pg} / \mathrm{mL}), \mathrm{TNF}-\mathrm{a}(>8.1 \mathrm{pg} / \mathrm{mL}), \mathrm{IL}-10$ $(>9.1 \mathrm{pg} / \mathrm{mL})$, and fibrosis in chest imaging examination were associated with increased risks of severe COVID-19. However, WBC $\left((4-10)^{*} 10^{9} / \mathrm{L}\right), \quad$ PLT $\left((125-350)^{*} 10^{9} / \mathrm{L} ;>350^{*} 10^{9} / \mathrm{L}\right)$, HB $(\geq 130 \mathrm{~g} / \mathrm{L}), \quad$ L $\left((0.5-1.1)^{*} 10^{9} / \mathrm{L} ;>1.1^{*} 10^{9} / \mathrm{L}\right), \quad$ ALB $(>40 \mathrm{~g} / \mathrm{L}), \quad$ GLU ((3.9-6.1) $\mathrm{mmol} / \mathrm{L} ;>6.1 \mathrm{mmol} / \mathrm{L})$, and BUN $((2.8-7.6) \mathrm{mmol} / \mathrm{L})$ were relevant to decreased risks of COVID-19 severity.

We further performed a multivariate ordinal logistic regression analysis to obtain the statistically significant independent determinants of COVID-19 illness severity in the final model (Table 7). Multivariable logistic regression analysis revealed that older age $(\mathrm{OR}=1.06,95 \% \mathrm{Cl}: 1.02-1.11 ; P=0.007)$, diabetes $(\mathrm{OR}=4.82,95 \% \mathrm{Cl}: 1.55-16.64 ; P=0.01)$, chronic liver disease $(\mathrm{OR}=6.53,95 \% \mathrm{Cl}: 1.38-35.81 ; P=0.025)$, percentage of neutrophils greater than $75 \%(\mathrm{OR}=9.12,95 \% \mathrm{Cl}: 2.49-41.41 ; P=0.002)$, CRP more than $4 \mathrm{mg} / \mathrm{L}(\mathrm{OR}=7.52,95 \% \mathrm{Cl}: 1.83-35.36 ; P=0.008)$, D-dimer more than $0.55 \mathrm{mg} / \mathrm{L}(\mathrm{OR}=19.96,95 \% \mathrm{Cl}: 2.37-272.47$ $P=0.013)$, IL-2R greater than $710 \mathrm{U} / \mathrm{mL}$ (OR 2.55, 95\% Cl: 1.06-6.58; $P=0.044)$, IL-8 more than $62 \mathrm{pg} / \mathrm{mL} \quad(\mathrm{OR}=236.35$, $95 \% \mathrm{Cl}: 5.62-384.1 ; P=0.018)$ and IL-10 more than $9.1 \mathrm{pg} / \mathrm{mL}$ (OR $=14.64,95 \% \mathrm{Cl}: 2.14-162.46 ; P=0.016)$ were independent risk factors associated with severe COVID-19 (Table 7).

\section{DISCUSSION}

Currently, the COVID-19 outbreak is still spreading around the world, posing a serious threat to human health. The origin and pathogenesis of COVID-19 are still unclear, and there are still no specific drugs to treat the disease. Unfortunately, some patients progress so rapidly that they develop respiratory failure and even die within a short period of time. Therefore, the potential for early identification of severe and critically ill patients has become a priority in improving effective treatment, reducing mortality and contributing to the allocation of medical resources. Therefore, we investigated the clinical characteristics and prognostic factors of COVID-19 patients in a hospital in Wuhan to identify the risk factors for illness severity, thus providing evidence for strengthening the effective management of COVID-19 patients hospitalized with severe illness. The median age of the 101 COVID-19 patients included in this study was 62 years (IQR 51-74); 50 (49.5\%) 
Table 4. Complications and treatments of 101 patients.

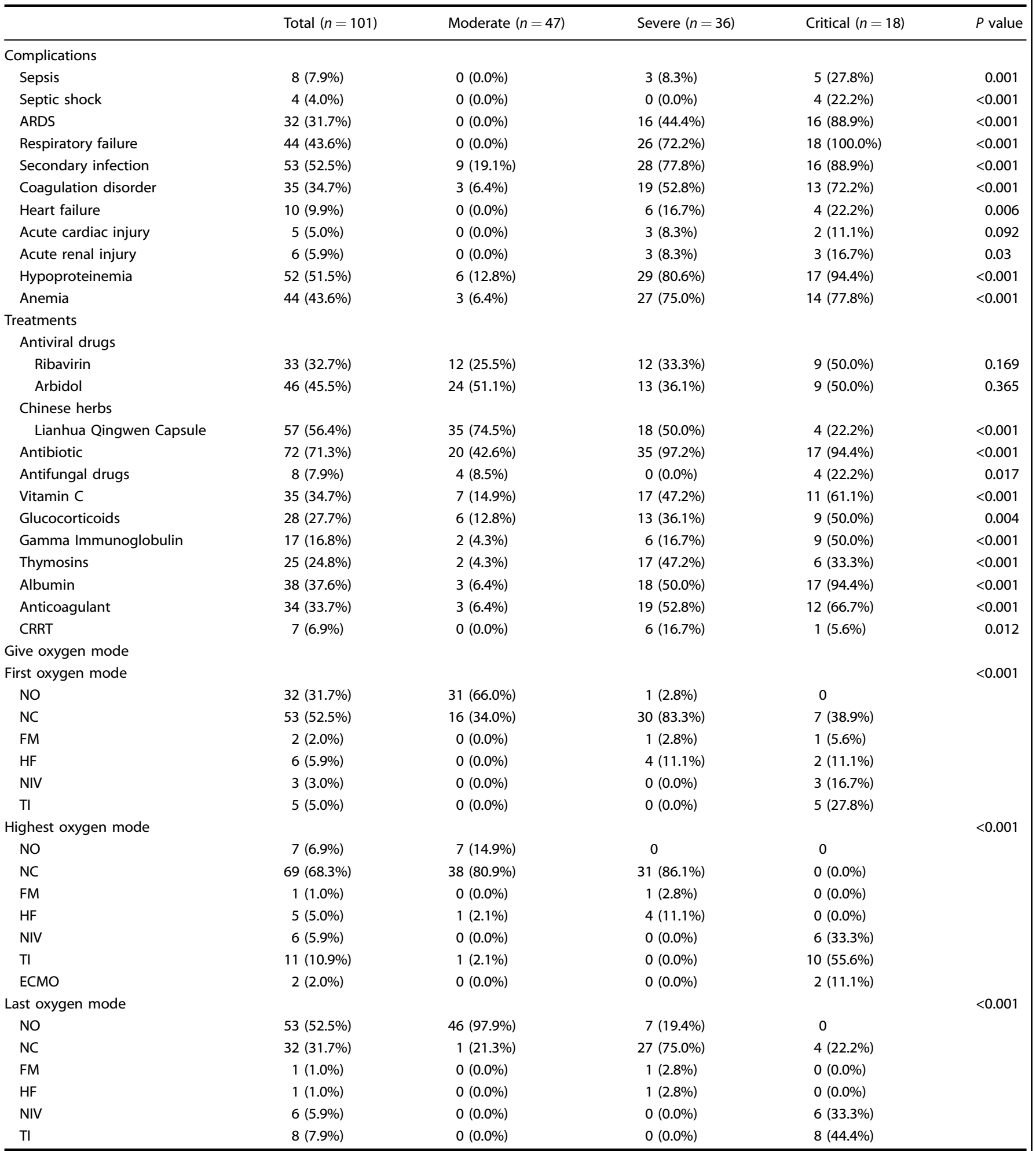

The first oxygen mode refers to the mode of oxygen therapy required by COVID-19 patients prior to admission. The highest oxygen therapy mode refers to the oxygen supply mode that the patients were unable to maintain the oxygen saturation at $93 \%$ or above, or had type II respiratory failure after previous oxygen therapy and needs to be changed. And the last oxygen mode refers to the oxygen supply mode required by the patients before discharging from the hospital. NO No oxygen inhalation, NC nasal catheter for oxygen, $F M$ face mask oxygen inhalation, $H F$ high-flow oxygen, NIV noninvasive ventilation, $T I$ tracheal intubation, ECMO extracorporeal membrane oxygenation. 
Table 5. The hospital course of 101 patients.

\begin{tabular}{lccccc}
\hline The hospital course (median [IQR]) & Total $(n=101)$ & Moderate $(n=47)$ & Severe $(n=36)$ & Critical $(n=18)$ & $P$ value \\
\hline Hospital time & $40.00[28.00,49.00]$ & $40.00[30.00,47.50]$ & $41.50[27.75,51.00]$ & $21.50[13.50,46.00]$ & 0.132 \\
Time from illness onset to first admission & $8.00[3.00,21.00]$ & $4.00[2.00,8.00]$ & $19.00[10.50,30.00]$ & $10.50[1.25,28.50]$ & $<0.001$ \\
Time from illness onset to ICU admission & $0.00[0.00,26.00]$ & $0.00[0.00,0.00]$ & $29.00[15.00,36.00]$ & $21.00[6.25,33.75]$ & $<0.001$ \\
Length of ICU stay & $0.00[0.00,11.00]$ & $0.00[0.00,0.00]$ & $9.00[6.00,15.25]$ & $12.00[5.00,20.75]$ & $<0.001$ \\
Time from admission to discharge/death & $16.00[9.00,22.00]$ & $20.00[14.00,27.00]$ & $10.00[7.75,16.25]$ & $13.50[5.00,18.50]$ & $<0.001$ \\
\hline
\end{tabular}

patients had hypertension, while 25 (24.8\%) and 22 (21.8\%) patients had diabetes and heart diseases, respectively. All the patients had a history of exposure to the epidemic area. Fever (65, $64.4 \%)$ and cough $(59,58.4 \%)$ were the most common clinical features. The imaging features were dominated by bilateral ground-glass shadows and consolidation foci in both lungs, while fibrosis occurred at a higher frequency in the severe or critical groups than in the moderate group. Furthermore, the multivariate logistic analysis indicated that older age, diabetes, chronic liver disease, percentage of neutrophils more than $75 \%$, CRP more than $4 \mathrm{mg} / \mathrm{L}$, D-dimer more than $0.55 \mathrm{mg} / \mathrm{L}$, IL-2R greater than $710 \mathrm{U} /$ $\mathrm{mL}$, IL-8 more than $62 \mathrm{pg} / \mathrm{mL}$, and IL-10 more than $9.1 \mathrm{pg} / \mathrm{mL}$ were independent variables associated with severe COVID-19.

The average age of the COVID-19 patients reported in our study (62 years) was higher than that of the patients reported by Zhou et al. and Lian et al. from Wuhan (56 years and 45 years, respectively) $[4,5]$. The results showed that the average age of severe or critical patients was significantly higher than that of moderate patients, and multivariate logistic models revealed that older age was a risk factor for disease progression (OR $=1.06,95 \%$ $\mathrm{Cl}: 1.02-1.11 ; P=0.007)$. Older age has previously been reported as a critical independent predictor of mortality in SARS and MERS $[6,7]$. Likewise, older people were deemed to be most vulnerable to SARS-COV-2 infection by a series of studies. Yang et al. observed that nonsurvivors of COVID-19 infection were older than survivors [7]. Wu et al. also reported that older COVID-19 patients were at greater risk of ARDS and death, possibly due to their poor immune response [8], which was supported by our data. COVID-19 infection was more likely to occur in people with underlying conditions such as hypertension (49.5\%), diabetes (24.8\%) and heart disease $(21.8 \%)$, which was consistent with previous reports [4]. Other researchers also concluded that the most common comorbidities among COVID-19 patients with ARDS were hypertension (27\%), diabetes (19\%) and cardiovascular disease (6\%). Studies have reported that there is currently no evidence that hypertension is associated with the prognosis of COVID-19 [9]. However, the fact that hypertension and other forms of cardiovascular disease are often found in patients with COVID19 infection has emphasized the importance of controlling blood pressure to reduce the disease burden. In addition, studies have shown that patients with diabetes are more likely to have severe COVID-19, and diabetes is considered a risk factor for death in severe COVID-19 patients [10]. It was found that the basement membrane of the lung is thickened in diabetic patients at autopsy, which may affect the function of pulmonary diffusion [11]. Consistently, our study found that patients with diabetes had a 4.82 (95\% Cl: $1.55-16.64 ; P=0.01)$ times greater risk of having worse severity of illness than patients without diabetes. Therefore, intensive treatment of diabetes should be considered in the management of COVID-19 patients. Furthermore, our multivariate logistic analysis indicated that the presence of chronic liver disease was an independent significant factor of COVID-19 illness severity, with an OR of 6.53 (95\% Cl: $1.38-35.81 ; P=0.025)$. Research has revealed that chronic liver diseases are more common in younger adults ( $<65$ years) [12]. A meta-analysis showed that COVID-19 patients with liver disease or CKD had an increased risk of severity and mortality, with a prevalence of $3 \%$ in patients with liver disease (95\% Cl; $2 \%-3 \%)$. Among COVID-19 patients with underlying liver disease, severe cases accounted for $57.33 \%(43 / 75)$, with a mortality rate of $17.65 \%$ [13]. Biomarkers of liver injuries have been reported to increase in COVID-19 patients by many studies; however, the mechanisms need to be explored $[14,15]$. The angiotensin II-converting enzyme (ACE2) receptor, which plays a key role in the "docking" and replication of SARSCOV-2 virus, has been reported to be expressed by cholangiocytes [16], suggesting that the binding of SARS-CoV-2 to the biliary epithelium leads to biliary dysfunction [17].

In terms of clinical symptoms, fever and cough occurred in most patients, while the incidence of chest tightness or dyspnea was also higher. The rest of the symptoms were fatigue, diarrhea and myalgia. Due to the nonspecific and diverse symptoms of COVID19 infection, early clinical diagnosis should be emphasized, taking into account the possibility of COVID-19 infection. In severe or critical patients, the levels of inflammatory indicators such as WBC, $\mathrm{N}, \mathrm{N} \%, \mathrm{NLR}, \mathrm{CRP}$ and ESR increased compared with those in moderate patients, which was associated with more complicated secondary infections in critically ill patients and a worse prognosis. Terpos et al. [18]. showed that patients with COVID-19 experienced a significant decrease in lymphocytes and a sharp increase in cytokines $\sim 7-14$ days after the initial symptoms appeared. Simultaneously, neutrophils increased significantly in the second week, which was partly attributed to the inhibition of neutrophil apoptosis by the production of a large number of cytokines and inflammatory mediators. Zhang et al. found that the N\% and NLR values in the critical group were higher than those in the moderate and severe groups [19]. Here, multivariate logistic regression analysis identified that the risk of having worse severity of illness was higher for patients with a higher percentage of neutrophils ( $>75 \%)(\mathrm{OR}=9.12,95 \% \mathrm{Cl}: 2.49-41.41 ; P=0.002)$ than for those with a lower neutrophil ratio $(\leq 75 \%)$. The significance of the NLR in the diagnosis and prognosis of viral infection has been emphasized by many studies. Han et al. found that the NLR is more sensitive than the neutrophil and lymphocyte count alone and may be a better diagnostic tool for screening patients infected with influenza virus [20]. Elevated NLR levels reflecting an enhanced inflammatory process may indicate a poor prognosis [21]. In our study, the NLR levels were related to a worse prognosis of COVID-19 in the univariate analysis, which was consistent with findings reported by others. Furthermore, we found that serum CRP levels increased markedly in refractory COVID-19 patients. The results of the multivariate model revealed that COVID-19 patients with higher CRP $(4 \mathrm{mg} / \mathrm{L})$ had a higher risk of exacerbation $(\mathrm{OR}=$ 7.52, 95\% Cl: $1.83-35.36 ; P=0.008)$ than patients with CRP less than or equal to $4 \mathrm{mg} / \mathrm{L}$. CRP is an acute phase protein that is rapidly synthesized by hepatocytes under inflammatory stimulation, such as microbial invasion or tissue damage, which can activate complement, enhance phagocytosis, and thus help remove pathogenic microorganisms that invade the body [22]. Liu et al. found that it was easier for COVID-19 patients with CRP > $41.8 \mathrm{mg} / \mathrm{L}$ to develop severe disease [23]. Similarly, studies have 
Table 6. Results of univariate ordinal logistic model for the severity of COVID-19.

\begin{tabular}{|c|c|c|c|c|}
\hline \multirow{2}{*}{$\begin{array}{l}\text { Variable } \\
\text { Clinical characteristics }\end{array}$} & \multicolumn{4}{|l|}{ Univariate } \\
\hline & Level & OR & $95 \% \mathrm{Cl}^{\mathrm{a}}$ & $P$ value \\
\hline \multirow[t]{2}{*}{ Sex } & Female & & & \\
\hline & Male & 1.84 & $0.87-3.97$ & 0.11 \\
\hline Age & & 1.08 & $1.05-1.12$ & $<0.001$ \\
\hline \multirow[t]{2}{*}{ Hypertension } & 0 & & & \\
\hline & 1 & 2.01 & $0.96-4.29$ & 0.065 \\
\hline \multirow[t]{2}{*}{ Diabetes } & 0 & & & \\
\hline & 1 & 4 & $1.72-9.59$ & 0.001 \\
\hline \multirow[t]{2}{*}{ Heart diseases } & 0 & & & \\
\hline & 1 & 5.33 & $2.16-13.7$ & $<0.001$ \\
\hline \multirow[t]{2}{*}{ Chronic renal disease } & 0 & & & \\
\hline & 1 & 4.59 & $1.83-12.0$ & 0.001 \\
\hline \multirow[t]{2}{*}{ Cerebrovascular diseases } & 0 & & & \\
\hline & 1 & 4.04 & $1.48-11.5$ & 0.006 \\
\hline \multirow[t]{2}{*}{ COPD } & 0 & & & \\
\hline & 1 & 2.18 & $0.64-7.49$ & 0.21 \\
\hline \multirow[t]{2}{*}{ Chronic liver disease } & 0 & & & \\
\hline & 1 & 3.6 & $1.13-11.9$ & 0.03 \\
\hline \multirow[t]{2}{*}{ Fever } & 0 & & & \\
\hline & 1 & 0.71 & $0.33-1.51$ & 0.37 \\
\hline \multirow[t]{2}{*}{ Diarrhea } & 0 & & & \\
\hline & 1 & 0.37 & $0.11-1.08$ & 0.069 \\
\hline \multirow[t]{2}{*}{ Fatigue } & 0 & & & \\
\hline & 1 & 1.56 & $0.68-3.62$ & 0.29 \\
\hline \multirow[t]{2}{*}{ Cough } & 0 & & & \\
\hline & 1 & 0.8 & $0.38-1.69$ & 0.56 \\
\hline \multirow[t]{2}{*}{ Sputum } & 0 & & & \\
\hline & 1 & 1.17 & $0.31-4.29$ & 0.81 \\
\hline \multirow[t]{2}{*}{ Chest distress } & 0 & & & \\
\hline & 1 & 0.7 & $0.33-1.46$ & 0.34 \\
\hline \multirow[t]{2}{*}{ Dyspnea } & 0 & & & \\
\hline & 1 & 1.61 & $0.75-3.47$ & 0.23 \\
\hline \multirow[t]{2}{*}{ Myalgia } & 0 & & & \\
\hline & 1 & 1.63 & $0.46-5.75$ & 0.44 \\
\hline WBC $\left(* 10^{9} / \mathrm{L}\right)$ & $<4$ & - & - & \\
\hline & $4-10$ & 0.72 & $0.20-2.75$ & $<0.001$ \\
\hline & $>10$ & 5.14 & $1.15-24.7$ & $<0.001$ \\
\hline $\mathrm{HB}(\mathrm{g} / \mathrm{L})$ & $<130$ & - & - & \\
\hline & $\geq 130$ & 0.19 & $0.07-0.49$ & $<0.001$ \\
\hline PLT $\left(* 10^{9} / \mathrm{L}\right)$ & $<125$ & - & - & \\
\hline & $125-350$ & 0.04 & $0.01-0.13$ & $<0.001$ \\
\hline & $>350$ & 0.22 & $0.04-1.05$ & $<0.001$ \\
\hline N\% & $\leq 75$ & - & - & \\
\hline & $>75$ & 20.9 & $7.96-63.3$ & $<0.001$ \\
\hline $\mathrm{L}\left({ }^{*} 10^{9} / \mathrm{L}\right)$ & $<0.5$ & - & - & \\
\hline & $0.5-1.1$ & 0.42 & $0.10-1.61$ & $<0.001$ \\
\hline & $>1.1$ & 0.03 & $0.01-0.11$ & $<0.001$ \\
\hline$N\left(* 10^{9} / L\right)$ & $<1.8$ & - & - & \\
\hline & $1.8-6.3$ & 1.17 & $0.21-8.97$ & $<0.001$ \\
\hline & $>6.3$ & 11.7 & $1.86-100$ & $<0.001$ \\
\hline NLR & & 1.22 & $1.14-1.33$ & $<0.001$ \\
\hline CRP (mg/L) & $\leq 4$ & - & - & \\
\hline & $>4$ & 31.4 & $11.5-97.8$ & $<0.001$ \\
\hline ESR (mm/h) & $\leq 20$ & - & - & \\
\hline & $>20$ & 7.57 & $3.29-18.5$ & $<0.001$ \\
\hline PCT (ng/mL) & $\leq 0.05$ & - & - & \\
\hline & $>0.05$ & 17.4 & $6.72-50.9$ & $<0.001$ \\
\hline
\end{tabular}

Table 6. continued

\begin{tabular}{|c|c|c|c|c|}
\hline \multirow{2}{*}{$\begin{array}{l}\text { Variable } \\
\text { Clinical characteristics }\end{array}$} & \multicolumn{4}{|c|}{ Univariate } \\
\hline & Level & OR & $95 \% \mathrm{Cl}^{\mathrm{a}}$ & $P$ value \\
\hline \multirow{2}{*}{ ALT (IU/L) } & $\leq 45$ & - & - & \\
\hline & $>45$ & 0.44 & $0.15-1.17$ & 0.1 \\
\hline \multirow{2}{*}{ GOT (IU/L) } & $\leq 35$ & - & - & \\
\hline & $>35$ & 2.79 & $1.03-7.68$ & 0.043 \\
\hline \multirow[t]{2}{*}{ ALB (g/L) } & $\leq 40$ & - & - & \\
\hline & $>40$ & 0.1 & $0.02-0.32$ & $<0.001$ \\
\hline \multirow[t]{2}{*}{ TBIL $(\mu \mathrm{mol} / \mathrm{L})$} & $\leq 21$ & - & - & \\
\hline & $>21$ & 5.92 & $1.51-26.1$ & 0.011 \\
\hline \multirow[t]{3}{*}{ GLU (mmol/L) } & $<3.9$ & - & - & \\
\hline & $3.9-6.1$ & 0.17 & $0.03-0.97$ & $<0.001$ \\
\hline & $>6.1$ & 0.79 & $0.12-4.81$ & \\
\hline \multirow{3}{*}{ BUN (mmol/L) } & $<2.8$ & - & - & \\
\hline & $2.8-7.6$ & 0.71 & $0.15-3.87$ & $<0.001$ \\
\hline & $>7.6$ & 8.85 & $1.68-54.8$ & \\
\hline \multirow[t]{2}{*}{$\mathrm{CR}(\mu \mathrm{mol} / \mathrm{L})$} & $\leq 110$ & - & - & \\
\hline & $>110$ & 8.17 & $3.03-23.6$ & $<0.001$ \\
\hline \multirow[t]{2}{*}{ UA $(\mu \mathrm{mol} / \mathrm{L})$} & $\leq 357$ & - & - & \\
\hline & $>357$ & 0.9 & $0.41-1.93$ & 0.78 \\
\hline \multirow{2}{*}{ CKI (ng/mL) } & $\leq 4.97$ & - & - & \\
\hline & $>4.97$ & 9.04 & $2.88-31.2$ & $<0.001$ \\
\hline \multirow[t]{2}{*}{ Mb (ng/mL) } & $\leq 65$ & - & - & \\
\hline & $>65$ & 5.3 & $2.24-13.1$ & $<0.001$ \\
\hline \multirow[t]{2}{*}{ TNI (ng/mL) } & $\leq 0.04$ & - & - & \\
\hline & $>0.04$ & 3.05 & $1.24-7.66$ & 0.015 \\
\hline \multirow[t]{2}{*}{ CK (IU/L) } & $\leq 145$ & - & - & \\
\hline & $>145$ & 2.98 & $0.76-12.1$ & 0.11 \\
\hline \multirow[t]{2}{*}{ LDH (IU/L) } & $\leq 243$ & - & - & \\
\hline & $>243$ & 12.8 & $5.21-34.6$ & $<0.001$ \\
\hline \multirow[t]{2}{*}{ PT (s) } & $\leq 13$ & - & - & \\
\hline & $>13$ & 9.03 & $3.48-25.2$ & $<0.001$ \\
\hline \multirow[t]{2}{*}{ D-dimer (mg/L) } & $\leq 0.55$ & - & - & \\
\hline & $>0.55$ & 56.7 & $14.9-376$ & $<0.001$ \\
\hline \multirow[t]{2}{*}{ IL-6 (pg/mL) } & $\leq 7$ & - & - & \\
\hline & $>7$ & 42.1 & $14.5-144$ & $<0.001$ \\
\hline \multirow[t]{3}{*}{ IL-2R (U/mL) } & $<223$ & - & - & \\
\hline & $223-710$ & 2.76 & $0.97-8.73$ & $<0.001$ \\
\hline & $>710$ & 36.4 & $10.5-147$ & $<0.001$ \\
\hline |L-8 (pg/mL) & $\leq 62$ & - & - & \\
\hline & $>62$ & 54 & $8.66-1058$ & $<0.001$ \\
\hline TNF- $\alpha(p g / m L)$ & $\leq 8.1$ & - & - & \\
\hline & $>8.1$ & 13.9 & $5.73-36.7$ & $<0.001$ \\
\hline IL-10 (pg/mL) & $\leq 9.1$ & - & - & \\
\hline & $>9.1$ & 16.3 & $5.24-57.7$ & $<0.001$ \\
\hline Consolidation & 0 & & & \\
\hline & 1 & 1.98 & $0.83-4.98$ & 0.13 \\
\hline GGO & 0 & & & \\
\hline & 1 & 3.37 & $0.74-23.9$ & 0.12 \\
\hline Subpleural distribution & 0 & & & \\
\hline & 1 & 0.62 & $0.29-1.30$ & 0.21 \\
\hline Bilateral involvement & 0 & & & \\
\hline & 1 & 0.65 & $0.17-2.56$ & 0.52 \\
\hline Fibrosis & 0 & & & \\
\hline & 1 & 2.22 & $1.05-4.76$ & 0.037 \\
\hline
\end{tabular}


Table 7. Results of multivariate ordinal logistic model for the severity of COVID-19.

\begin{tabular}{|c|c|c|c|c|}
\hline \multirow{2}{*}{$\begin{array}{l}\text { Variable } \\
\text { Clinical characteristics }\end{array}$} & \multicolumn{4}{|c|}{ Multivariate } \\
\hline & Level & OR & $95 \% \mathrm{Cl}^{\mathrm{a}}$ & $P$ value \\
\hline Age & & 1.06 & $1.02-1.11$ & 0.007 \\
\hline \multirow[t]{2}{*}{ Diabetes } & 0 & & & \\
\hline & 1 & 4.82 & $1.55-16.64$ & 0.01 \\
\hline \multirow[t]{2}{*}{ Chronic liver disease } & 0 & & & \\
\hline & 1 & 6.53 & $1.38-35.81$ & 0.025 \\
\hline \multirow[t]{2}{*}{ N\% } & $\leq 75$ & - & - & \\
\hline & $>75$ & 9.12 & $2.49-41.41$ & 0.002 \\
\hline \multirow[t]{2}{*}{ CRP (mg/L) } & $\leq 4$ & - & - & \\
\hline & $>4$ & 7.52 & $1.83-35.36$ & 0.008 \\
\hline \multirow[t]{2}{*}{ Fibrosis } & 0 & & & \\
\hline & 1 & 2.37 & $0.81-7.36$ & 0.125 \\
\hline \multirow[t]{2}{*}{ PCT (ng/mL) } & $\leq 0.05$ & - & - & \\
\hline & $>0.05$ & 3.56 & $0.78-17.86$ & 0.112 \\
\hline \multirow[t]{2}{*}{ D-dimer (mg/L) } & $\leq 0.55$ & - & - & \\
\hline & $>0.55$ & 19.96 & $2.37-272.47$ & 0.013 \\
\hline \multirow[t]{2}{*}{ IL-6 (pg/mL) } & $\leq 7$ & - & - & \\
\hline & $>7$ & 1.44 & $0.23-8.22$ & 0.685 \\
\hline \multirow[t]{3}{*}{ IL-2R (U/mL) } & $<223$ & - & - & \\
\hline & $223-710$ & & & \\
\hline & $>710$ & 2.55 & $1.06-6.58$ & 0.044 \\
\hline \multirow[t]{2}{*}{ IL-8 (pg/mL) } & $\leq 62$ & - & - & \\
\hline & $>62$ & 236.35 & $5.62-384.10$ & 0.018 \\
\hline \multirow[t]{2}{*}{ IL-10 (pg/mL) } & $\leq 9.1$ & - & - & \\
\hline & $>9.1$ & 14.64 & $2.14-162.46$ & 0.016 \\
\hline
\end{tabular}

shown that the median CRP value is approximately $40 \mathrm{mg} / \mathrm{L}$ for survivors and $125 \mathrm{mg} / \mathrm{L}$ for nonsurvivors, which is closely related to disease severity and prognosis [24].

Coagulation disorders are common in COVID-19 patients, especially in severe cases [25]. Multiple studies have confirmed that D-dimer dynamics can reflect the severity of COVID-19 and that elevated levels are associated with poor outcomes in COVID-19 patients. In a multicentric retrospective study, D-dimer levels $(\geq 0.5 \mathrm{mg} / \mathrm{L})$ were increased in 260 (46.4\%) of 560 confirmed COVID-19 patients and were more pronounced in severe patients (59.6\%) [26]. Another study showed that patients requiring ICU support had higher levels of D-dimer and prothrombin time (PT) on admission. Furthermore, among 201 patients with COVID-19 pneumonia, prolonged PT and increased D-dimer were associated with an increased risk of ARDS $(P<$ 001). In a retrospective cohort study, multivariate analysis showed that elevated D-dimer levels $(>1 \mathrm{~g} / \mathrm{L})$ were closely related to in-hospital mortality [4]. In our study, D-dimer and PT levels were increased in severe or critical COVID-19 patients, and a multivariate model revealed that patients with D-dimer greater than $0.55 \mathrm{mg} / \mathrm{L}$ had a higher risk of disease deterioration (OR $=19.96,95 \% \mathrm{Cl}: 2.37-272.47 ; P=0.013)$. The elevated $\mathrm{D}-$ dimer level reflects hypercoagulability in vivo and may promote the formation of deep venous thrombosis or even the possibility of lethal pulmonary thromboembolism (PE) caused by detachment of thrombi in COVID-19. Therefore, the risk of venous thrombus embolism in all hospitalized patients must be assessed, and thromboprophylaxis should be undertaken for all these high-risk patients [27].

In terms of laboratory tests, the lymphocyte counts decreased in most patients, and the absolute value of lymphocytes was negatively correlated with the severity of COVID-19, indicating that COVID-19 mainly attacked lymphocytes. T lymphocytes play an important role in viral clearance, with $\mathrm{CD}^{+}$cytotoxic T cells (CTLs) and $\mathrm{CD}^{+}{ }^{+}$helper T cells (Th) enhancing the host's ability to remove pathogens. However, continuous stimulation by the virus may lead to T-cell exhaustion, resulting in reduced immune function and aggravation of the patient's condition. Studies have shown a decrease in all subsets of lymphocytes, including total T cells, $\mathrm{CD}^{+}$ and $\mathrm{CD}^{+} \mathrm{T}$ cells, memory and regulatory $\mathrm{T}$ cells, and B cells, in COVID-19 infection. Moreover, lower lymphocyte counts are closely correlated with worse prognosis [28, 29]. Due to the limited detection conditions, we failed to detect lymphocyte subsets in our clinical work. Nevertheless, urgent intervention may be necessary to prevent the development of disease in patients with lower T-cell counts. Cytokine storms have been considered an important factor in ARDS and have also been associated with respiratory viral infections, such as SARS in 2000 and H7N9 infection in 2013 [30, 31]. In addition, studies have shown that the number of $T$ cells is negatively correlated with serum IL-6, IL-10, and TNF-a [32]. Here, we found that serum IL-2R, IL-6, IL-8, TNF- $a$, and IL-10 levels were elevated in severe/critical patients compared with moderate patients. Furthermore, the multivariate logistic models indicated that higher levels of IL-8 (>62 pg/mL) were independent significant predictors of illness severity, with an OR of $236.35(95 \% \mathrm{Cl}$ : 5.62-384.10; $P=0.018$ ). IL-8, also known as CXCL8, is a key regulator of lung neutrophil and monocyte chemotaxis. Studies have shown that IL-8 may promote the inflammatory response by recruiting immune cells into the lung, which may be directly involved in the pathogenesis of ARDS [33,34]. It has been shown that increased plasma IL-8 levels are related to the potential mortality of patients with acute lung injury [35]. Consistent with previous investigations [36], our study found that plasma proinflammatory cytokines IL-8, along with IL-6 and TNF-a, were significantly increased in both severe and critical cases and were positively correlated with COVID-19 severity, suggesting that a vigorous inflammatory response plays a crucial role in the pathogenesis of SARS-COV-2 infection. IL-10 is an inhibitory cytokine that can not only inhibit T-cell proliferation but also induce T-cell exhaustion. It has been reported that higher levels of IL-10 are associated with better survival of ARDS patients and that lower IL-10 levels are correlated with more severe illness in SARS patients $[37,38]$. However, the IL-10 level was found to be significantly higher in severe MERS patients than in mild MERS patients and was positively correlated with mortality [39]. Similarly, we demonstrated here that severe COVID-19 patients displayed significantly higher levels of IL-10 following SARS-CoV-2 infection, and an IL-10 level greater than $9.1 \mathrm{pg} / \mathrm{mL}$ was an independent predictor of COVID-19 severity, with an OR of 14.64 (95\% Cl: $2.14-162.46 ; P=0.016)$ in the multivariate analysis. These results may be due to the antiinflammatory regulation of IL-10, which may be a compensatory response to the increased pro-inflammatory cytokines. In addition, elevation of IL-10 is associated with increased expression of the Tcell exhaustion markers PD- 1 and Tim-3, and their ability to clear viral infections is thus impaired, especially in severe COVID-19 patients. Therefore, the increase in IL-10 levels may be associated with poor prognosis. In contrast to IL-10, serum IL-2R is considered a marker of T-cell activation [40]. In patients with acute lung injury, IL$2 \mathrm{R}$ concentrations have been shown to be higher than those in patients without ALI, with enhanced T-cell activity [41, 42]. A study carried out by $\mathrm{Ni}$ et al. found that IL-2R levels were significantly associated with disease severity, showing markedly higher serum levels in severe COVID-19 patients [43]. Our multivariate logistic models revealed that COVID-19 patients with IL-2R levels greater than $710 \mathrm{U} / \mathrm{mL}$ had an increased risk of disease progression 
$(\mathrm{OR}=2.55,95 \% \mathrm{Cl}: 1.06-6.58 ; P=0.044)$ compared to patients with IL-2R levels less than $223 \mathrm{U} / \mathrm{mL}$, indicating that an increase in IL-2R levels was associated with poor prognosis. Based on our results, IL-8, IL-10, and IL-2R levels can serve as potential prognostic indicators for risk stratification in COVID-19 patients, which further suggests that both pro-inflammatory and anti-inflammatory responses may occur in COVID-19 patients; however, the role of immunosuppression in disease progression remains to be determined by further research.

The rapid spread of COVID-19 has prompted efforts to find effective treatments, mainly for its severe form. Therefore, factors that predict progression of the disease to a more severe form are most urgently needed to be identified. According to our findings, older age, diabetes, chronic liver disease, percentage of neutrophils above $75 \%$, CRP more than $4 \mathrm{mg} / \mathrm{L}$, IL-2R greater than $710 \mathrm{U} / \mathrm{mL}$, IL-8 more than $62 \mathrm{pg} / \mathrm{mL}$, and IL-10 above $9.1 \mathrm{pg} / \mathrm{mL}$ were independent risk factors for severe COVID-19 pneumonia. Furthermore, the multivariate logistic analysis indicated that older age, diabetes, chronic liver disease, percentage of neutrophils above $75 \%$, CRP more than $4 \mathrm{mg} / \mathrm{L}$, D-dimer more than $0.55 \mathrm{mg} / \mathrm{L}$, IL-2R greater than $710 \mathrm{U} / \mathrm{mL}$, IL-8 more than $62 \mathrm{pg} / \mathrm{mL}$, and IL-10 above $9.1 \mathrm{pg} / \mathrm{mL}$ were independent variables associated with severe COVID-19.

Thus, in specific patients, treatment targeting pro-inflammatory cytokines such as IL-8 and IL-2R suppresses excessive inflammation, and some cytokines theoretically trigger immune recovery. Given the severity of this global public health emergency, although our work was based on a small sample size, we believe that this report is important for understanding the clinical characteristics of COVID-19 infection and identifying the risk factors associated with the severity of the disease.

\section{ACKNOWLEDGEMENTS}

We really acknowledge all the medical workers fighting shoulder to shoulder in Wuhan who were involved in the diagnosis and treatment of the patients.

\section{AUTHOR CONTRIBUTIONS}

XQL and SX collected and organized the clinical data. JBX were responsible for reviewing data and ensuring the accuracy of data. $X Q L$ wrote the main paper; HG, $\mathrm{QM}$, and XHX analyzed the data and assisted the statistical analysis; HDJ designed this study and directed the overall project. All authors reviewed the paper.

\section{ADDITIONAL INFORMATION}

Supplementary information The online version contains supplementary material available at https://doi.org/10.1038/s41401-021-00627-2.

Competing interests: The authors declare no competing interests.

\section{REFERENCES}

1. Huang C, Wang Y, Li X, Ren L, Zhao J, Hu Y, et al. Clinical features of patients infected with 2019 novel coronavirus in Wuhan, China. Lancet. 2020;395:497-506.

2. Lai CC, Shih TP, Ko WC, Tang HJ, Hsueh PR. Severe acute respiratory syndrome coronavirus 2 (SARS-CoV-2) and coronavirus disease-2019 (COVID-19): the epidemic and the challenges. Int J Antimicrob Agents. 2020;55:105924.

3. R Core Team. R: A language and environment for statistical computing. Vienna, Austria: R Foundation for Statistical Computing; 2017.

4. Zhou F, Yu T, Du R, Fan G, Liu Y, Liu Z, et al. Clinical course and risk factors for mortality of adult inpatients with COVID-19 in Wuhan, China: a retrospective cohort study. Lancet. 2020;395:1054-62.

5. Lian J, Jin X, Hao S, Jia H, Cai H, Zhang X, et al. Epidemiological, clinical, and virological characteristics of 465 hospitalized cases of coronavirus disease 2019 (COVID-19) from Zhejiang Province in China. Influenza Other Respir Viruses. 2020;14:564-74.

6. Hong KH, Choi JP, Hong SH, Lee J, Kwon JS, Kim SM, et al. Predictors of mortality in Middle East respiratory syndrome (MERS). Thorax. 2018;73:286-9.

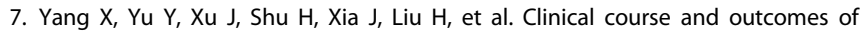
critically ill patients with SARS-CoV-2 pneumonia in Wuhan, China: a singlecentered, retrospective, observational study. Lancet Respir Med. 2020;8:475-81.
8. Wu C, Chen X, Cai Y, Ja Xia, Zhou X, Xu S, et al. Risk factors associated with acute respiratory distress syndrome and death in patients with coronavirus disease 2019 pneumonia in Wuhan, China. JAMA Intern Med. 2020;180:934-43.

9. Schiffrin EL, Flack JM, Ito S, Muntner P, Webb RC. Hypertension and COVID-19. Am J Hypertens. 2020;33:373-4.

10. Weynand B, Jonckheere A, Frans A, Rahier J. Diabetes mellitus induces a thickening of the pulmonary basal lamina. Respiration. 1999;66:14-9.

11. Liu WJ, Zhao M, Liu K, Xu K, Wong G, Tan W, et al. T cell immunity of SARSCoV: implications for vaccine development against MERSCoV. Antivir Res. 2017; 137:82-92.

12. Palmieri L, Vanacore N, Donfrancesco C, Lo Noce C, Canevelli M, Punzo O, et al. Clinical characteristics of hospitalized individuals dying with COVID-19 by age group in Italy. J Gerontol A Biol Sci Med Sci. 2020;75:1796-800.

13. Oyelade T, Alqahtani J, Canciani G. Prognosis of COVID-19 in patients with liver and kidney diseases: an early systematic review and meta-analysis. Trop Med Infect Dis. 2020;5:80.

14. Chen N, Zhou M, Dong X, Qu J, Gong F, Han Y, et al. Epidemiological and clinical characteristics of 99 cases of 2019 novel coronavirus pneumonia in Wuhan, China: a descriptive study. Lancet. 2020;395:507-13.

15. Wang D, Hu B, Hu C, Zhu F, Liu X, Zhang J, et al. Clinical characteristics of 138 hospitalized patients with 2019 novel coronavirus-infected pneumonia in Wuhan, China. JAMA. 2020;323:1061-9.

16. Chai $X$, Hu L, Zhang Y, Han W, Lu Z, Ke A, et al. Specific ACE2 expression in cholangiocytes may cause liver damage after 2019-nCoV infection. BioRxiv. 2020. https://doi.org/10.1101/2020.02.03.931766.

17. Zhang C, Shi L, Wang FS. Liver injury in COVID-19: management and challenges. Lancet Gastroenterol Hepatol. 2020;5:428-30.

18. Terpos E, Ntanasis-Stathopoulos I, Elalamy I, Kastritis E, Sergentanis TN, Politou M, et al. Hematological findings and complications of COVID-19. Am J Hematol. 2020;95:834-47.

19. Zhang HM, Cao XC, Kong M, Mao XL, Huang LF, He PW, et al. Clinical and hematological characteristics of 88 patients with COVID-19. Int J Lab Hematol. 2020;42:780-7.

20. Han Q, Wen X, Wang L, Han X, Shen Y, Cao J, et al. Role of hematological parameters in the diagnosis of influenza virus infection in patients with respiratory tract infection symptoms. J Clin Lab Anal. 2020:e23191.

21. Guzik TJ, Mohiddin SA, Dimarco A, Patel V, Savvatis K, et al. COVID-19 and the cardiovascular system: implications for risk assessment, diagnosis, and treatment options. Cardiovasc Res. 2020;116:1666-87.

22. Hahn WH, Song JH, Kim H, Park S. Is procalcitonin to C-reactive protein ratio useful for the detection of late onset neonatal sepsis? J Matern Fetal Neonatal Med. 2018;31:822-6.

23. Liu Fang, Li Lin, Xu MD, Wu J, Luo D, et al. Prognostic value of interleukin-6, Creactive protein, and procalcitonin in patients with COVID-19. J Clin Virol. 2020;127:104370.

24. Ruan Q, Yang K, Wang W, Jiang L, Song J. Clinical predictors of mortality due to COVID-19 based on an analysis of data of 150 patients from Wuhan, China. Intensive Care Med. 2020;46:846-8.

25. Deng Y, Liu W, Liu K, Fang YY, Shang J, Zhou L, et al. Clinical characteristics of fatal and recovered cases of coronavirus disease 2019 (COVID-19) in Wuhan, China: a retrospective study. Chin Med J. 2020;133:1261-7.

26. Guan WJ, Ni ZY, Hu Y, Liang WH, Ou CQ, He JX, et al. Clinical characteristics of coronavirus disease 2019 in China. N Engl J Med. 2020;382:1708-20.

27. Kahn SR, Lim W, Dunn AS, Cushman M, Dentali F, Akl EA, et al. Prevention of VTE in nonsurgical patients: antithrombotic therapy and prevention of thrombosis, 9th ed: American College of Chest Physicians Evidence-Based Clinical Practice Guidelines. Chest. 2012;141:e195S-226S.

28. Qin C, Zhou L, Hu Z, Zhang S, Yang S, Tao Y, et al. Dysregulation of immune response in patients with COVID-19 in Wuhan, China. Clin Infect Dis. 2020;71:762-8

29. Wang F, Nie J, Wang H, Zhao Q, Xiong Y, Deng L, et al. Characteristics of peripheral lymphocyte subset alteration in COVID-19 pneumonia. J Infect Dis. 2020;221:1762-9.

30. Channappanavar R, Perlman S. Pathogenic human coronavirus infections: causes and consequences of cytokine storm and immunopathology. Semin Immunopathol. 2017;39:529-39.

31. Huang KJ, Su IJ, Theron M, Wu YC, Lai SK, Liu CC, et al. An interferongammarelated cytokine storm in SARS patients. J Med Virol. 2005;75:185-94.

32. Diao B, Wang C, Tan $Y$, Chen X, Liu Y, Ning L, et al. Reduction and functional exhaustion of T cells in patients with coronavirus disease 2019 (COVID-19). Front Immunol. 2020;11:827.

33. García-Laorden MI, Lorente JA, Flores C, Slutsky AS, Villar J. Biomarkers for the acute respiratory distress syndrome: how to make the diagnosis more precise. Ann Transl Med. 2017;5:283. 
34. Goodman RB, Strieter RM, Martin DP, Steinberg KP, Milberg JA, Maunder RJ, et al. Inflammatory cytokines in patients with persistence of the acute respiratory distress syndrome. Am J Respir Crit Care Med. 1996;154:602-11.

35. Parsons PE, Eisner MD, Thompson BT, Matthay MA, Ancukiewicz M, Bernard $\mathrm{GR}$, et al. Lower tidal volume ventilation and plasma cytokine markers of inflammation in patients with acute lung injury. Crit Care Med. 2005;33:1-6. discussion 230-2.

36. Zeng $\mathrm{Z}$, Yu H, Chen $\mathrm{H}$, Qi W, Chen L, Chen $\mathrm{G}$, et al. Longitudinal changes of inflammatory parameters and their correlation with disease severity and outcomes in patients with COVID-19 from Wuhan, China. Crit Care. 2020;24:525.

37. Miyaoka K, Iwase M, Suzuki R, Kondo G, Watanabe H, Ito D, et al. Clinical evaluation of circulating interleukin- 6 and interleukin-10 levels after surgery-induced inflammation. J Surg Res. 2005;125:144-50.

38. Chien JY, Hsueh PR, Cheng WC, Yu CJ, Yang PC. Temporal changes in cytokine/ chemokine profiles and pulmonary involvement in severe acute respiratory syndrome. Respirology. 2006;11:715-22.
39. Min CK, Cheon S, Ha NY, Sohn KM, Kim Y, Aigerim A, et al. Comparative and kinetic analysis of viral shedding and immunological responses in MERS patients representing a broad spectrum of disease severity. Sci Rep. 2016;6:25359.

40. Lin M, Park S, Hayden A, Giustini D, Trinkaus M, Pudek M, et al. Clinical utility of soluble interleukin-2 receptor in hemophagocytic syndromes: a systematic scoping review. Ann Hematol. 2017;96:1241-51.

41. Karim AF, Eurelings LEM, Bansie RD, van Hagen PM, van Laar JAM, Dik WA. Soluble interleukin-2 receptor: a potential marker for monitoring disease activity in IgG4-related disease. Mediators Inflamm. 2018;2018:6103064. https://doi.org/ $10.1155 / 2018 / 6103064$.

42. Takala A, Jousela I, Takkunen O, Kautiainen $H$, Jansson SE, Orpana A, et al. A prospective study of inflammation markers in patients at risk of indirect acute lung injury. Shock. 2002;17:252-7.

43. Ni M, Tian FB, Xiang DD, Yu B. Characteristics of inflammatory factors and lymphocyte subsets in patients with severe COVID-19. J Med Virol. 2020;92:2600-6. 